\title{
Establishment and Characterisation of Metastatic Extraskeletal Ewing Sarcoma Mouse Models
}

\author{
CARMELO CERRA*, MICHAEL A. HARRIS* and CHRISTINE J. HAWKINS \\ Department of Biochemistry and Genetics, La Trobe Institute for Molecular Science, \\ La Trobe University, Melbourne, VIC, Australia
}

\begin{abstract}
Background/Aim: Ewing sarcomas most commonly arise in the bones, but can also manifest as extraskeletal tumours in soft tissues. Metastases from extraskeletal Ewing sarcomas occur in more diverse anatomical sites than skeletal tumours, and have poorer survival rates. Few animal models replicate the extraskeletal form of Ewing sarcoma, and those that have been developed do not reflect the widespread metastatic spread of these cancers. Materials and Methods: Luciferase-expressing Ewing sarcoma cells derived from a muscle tumour were intramuscularly or intravenously injected into nude mice. Results: Both models achieved metastatic spread to numerous sites including the lungs, liver, kidneys, and brain. We characterized the cellular composition of primary and metastatic tumours, observing a greater level of immune cell infiltration in metastases compared to primary intramuscular tumours. Conclusion: These pre-clinical models will hopefully facilitate the evaluation of novel therapies and contribute to better understanding the disease progression of metastatic extraskeletal Ewing sarcoma.
\end{abstract}

Sarcomas are a rare group of bone and soft tissue cancers of mesodermal origin. They usually originate in the bone, cartilage or soft tissue and are classified based on their histology and chromosomal translocations (1). Ewing sarcoma is a 'round cell sarcoma' which was first identified by James Ewing in 1921, when treating a 14 year old girl with a

This article is freely accessible online.

*These Authors contributed equally to this work.

Correspondence to: Christine J. Hawkins, Department of Biochemistry and Genetics, La Trobe Institute for Molecular Science, La Trobe University, Melbourne, Australia. E-mail: c.hawkins@latrobe.edu.au

Key Words: Ewing sarcoma, extraosseous, extraskeletal, mouse model, A673, metastasis. fractured ulna (2). It is the second most common bone cancer, behind osteosarcoma, and is most frequently diagnosed during adolescence (3). Although Ewing sarcoma usually develops in bones such as the pelvis and femur, a substantial minority of tumours arise in soft tissues (4-6). These extraskeletal (or extraosseous) Ewing sarcomas are rare in children, but account for up to half of adult Ewing sarcoma diagnoses (79). Approximately a quarter of Ewing sarcoma patients have detectable metastases at diagnosis (10). Metastatic spread of skeletal Ewing sarcoma occurs most commonly to the lungs, other bones, and bone marrow (11). Extraskeletal Ewing sarcoma spreads most frequently to the bones or lungs (12) but approximately $14 \%$ are metastases within other organs, such as abdominal organs, the peritoneum, brain, or heart (12, 13). Current treatments for Ewing sarcoma involve neoadjuvant chemotherapy, typically with vincristine, doxorubicin, cyclophosphamide, ifosfamide and etoposide, followed by surgery and/or radiotherapy (5). The incorporation of multiagent chemotherapy increased 5-year survival rates for localized disease from approximately $10 \%$ to $70 \%(14,15)$. Unfortunately, these therapies are less effective against Ewing sarcoma metastases, especially those derived from extraskeletal primary tumours: only a quarter of those patients survive for five years or more (7). The metastatic predilection of extraskeletal Ewing sarcoma differs from the more common skeletal form of the malignancy, so it is conceivable that optimal therapies for metastases emanating from skeletal versus extraskeletal Ewing sarcomas may differ.

The establishment and characterisation of authentic Ewing sarcoma mouse models would provide a means to better understand the metastatic processes and to evaluate potential new drug candidates in a preclinical setting. Although Ewing sarcomas feature distinct oncogenic chromosomal translocations (16), efforts to create genetically-engineered mouse models of this cancer type have so far been unsuccessful (17). Instead, available models entail introducing Ewing sarcoma cell lines or patient-derived tumour material into mice. Subcutaneous introduction of Ewing cells or patient-derived tumour material into mice can be tumourigenic, and the resulting xenografts can 
manifest authentic gene expression and tumour architecture (1821). However, they do not necessarily recapitulate the tumour microenvironment or metastatic pathways, nor the bioavailability of candidate therapies that researchers may wish to test. Some orthotopic models of skeletal Ewing sarcomas have been established, via introduction of skeletal Ewing sarcoma cells into the tibia or femur (22-25). Ewing cell lines generated from bone tumours, like TC71 (26) or SK-ES1 (27, 28), have also been xenografted into the gastrocnemius muscle of SCID/beige mice (29).

To our knowledge, only one orthotopic model of extraskeletal Ewing sarcoma has been published. The A673 cell line, which was derived from a Ewing sarcoma that arose in the muscle (30-32), was tumourigenic upon injection into the gastrocnemius muscle of BALB/c nude mice (33-36).

An urgent priority for Ewing sarcoma research is the identification of more effective therapies for metastatic disease. Our goal in this study was to create a model of metastatic extraskeletal Ewing sarcoma that reflects the diverse metastatic spread experienced by patients. In previous work, most mice that received injections of A673 cells into the gastrocnemius muscle developed lung pulmonary metastases 40-60 days post primary tumour resection (34-36), however spread to other anatomical sites was not observed. Interestingly, intratibial inoculation of A673 cells provoked metastases to other bones as well as the lungs (24), suggesting that the site of implantation can influence the pattern of metastatic spread. One aim of this study was to evaluate the metastatic potential of A673 cells following injection into the tibialis anterior, as mice tolerate quite large primary tumours in this muscle and osteosarcoma cell implantation into this site was tumourigenic and metastatic $(37,38)$.

Intravenously injecting immunodeficient mice with millions of A673 cells (so-called "experimental metastasis") only yielded lung metastases $(33,35,39,40)$. In models of other cancer types, the efficiency of experimental metastasis could be substantially enhanced by transiently depleting natural killer (NK) cells prior to the intravenous injection of cells (41, 42). Using this approach, metastases derived from the osteosarcoma cell line 143B were detected in many organs, including the lungs, liver, kidneys, and brain $(37,41)$. In this study, we explored the possibility that NK depletion may enhance the efficiency of experimental metastasis in the context of extraskeletal Ewing sarcoma, and perhaps facilitate spread to organs other than the lungs, modelling the diversity of metastatic sites observed clinically.

For each of these approaches, we documented tumour growth, spread and cellular composition.

\section{Materials and Methods}

Cell culture. Human A673 Ewing Sarcoma cells (provided by Dr Lucy Coupland) were authenticated by short tandem repeat (AGRF, Melbourne, Australia). They were cultured in DMEM media
(Invitrogen, Waltham, MA, USA) supplemented with 10\% FBS and cultured at $37^{\circ} \mathrm{C}$ in a humidified atmosphere of $5 \% \mathrm{CO}_{2}$. A673 cells were transfected with the pcDNA3.1(+)/Luc2=tdT plasmid (Addgene, Watertown, MA, USA) (43), a gift from Christopher Contag, to express luciferase and dTomato genes. Limiting dilution was used to isolate dTomato positive clones (44).

Animal studies. Animal experiments were conducted in accordance with Australian Code of Practice for the Care and Use of Animals for Scientific Purposes, as approved by the La Trobe Animal Ethics Committee (approval AEC 17-76). Five to six-week-old BALB/cFoxn1nu/Arc ("nude") mice were purchased from the Animal Resource Centre (Canning Vale, WA, Australia). Mice were housed at the La Trobe Animal Research facility in individual ventilated cages, with 12-h light/dark cycling and unrestricted access to food and water. Mice were monitored for tumour related symptoms and weighed each day. Euthanasia was performed by $\mathrm{CO}_{2}$ asphyxiation or cervical dislocation.

Tumour implantation and imaging. Mice bearing intramuscular A673-luc tumours were generated by injecting 50,000 A673-luc cells resuspended in $20 \mu \mathrm{l}$ of a 1:1 mixture of media and cultrex (Trevigen, Gaithersburg, MD, USA) into the left tibialis anterior muscle while under isoflurane induced anaesthesia. Experimental metastases were achieved by injecting 500,000 A673-luc cells intravenously 24 hours-post intraperitoneal injection of $50 \mu \mathrm{l}$ of anti-asialo GM1 (Fujifilm Wako, Osaka, Japan) or saline. Mice were imaged twice weekly and tumour burden quantitated as previously described (37).

Flow cytometry. Primary intramuscular tumours and metastases large enough to be excised from healthy tissue were minced with a scalpel blade and digested in PBS containing $0.1 \%$ collagenase and $0.2 \%$ dispase II (Sigma Aldrich, St. Louis, MO, USA) at $37^{\circ} \mathrm{C}$ for 30 min with shaking at $800 \mathrm{rpm}$ and passed through a $70 \mu \mathrm{m}$ cell strainer. Single cells were stained as previously described (37) with these antibodies: F4/80-PE-Cy7 clone BM8 \#25-4801-82 (ThermoFisher Scientific Scoresby, Scoresby, VIC, Australia), Ly6G-APC clone 1A8 \#560599 (BD Biosciences, Franklin Lakes, NJ, USA), and CD335/NKP46-BV421 clone 29A1.4 \#562850 (BD Biosciences), or a panel of isotype control antibodies bearing the same fluorophores, sourced from the same companies (\#25-432182; \#553932; \#562602). Data was generated using a CytoFLEX S (Beckman Coulter Life Sciences, Lane Cove West, NSW, Australia) and analysed using FlowJo 10.7 (BD Biosciences) software.

Tissue processing and histology. Tissue was processed, stained and sectioned as previously described (37).

Statistical analysis. All statistical analyses were performed using Prism 9.0 software (GraphPad, San Diego, CA, USA).

\section{Results}

Transient depletion of natural killer cells facilitated formation of A673 Ewing sarcoma metastases. Our aim in this study was to establish and characterise models of extraskeletal Ewing sarcoma that could be used to evaluate the efficacy of novel therapies. Human A673 Ewing sarcoma cells were selected because they were derived from a muscle 
Ewing tumour (30-32). The cells were engineered to express the reporter enzyme luciferase to enable in vivo monitoring of tumour development and spread after their introduction into $\mathrm{BALB} / \mathrm{c}$ nude mice.

We previously reported that transient depletion of natural killer (NK) cells by injecting mice with the anti-asialo GM1 antibody facilitates efficient formation of metastases in $\mathrm{BALB} / \mathrm{c}$ nude mice after intravenous injection of osteosarcoma cells (41). We therefore explored the impact of NK depletion on metastasis after intravenously injecting luciferase-expressing A673 cells. Previous studies used two million A673 cells to achieve experimental metastases (33, $39,40)$. We used fewer cells in the hope of achieving extravasation-mediated metastases rather than embolisms.

All five mice injected with half a million A673-luc cells without NK depletion remained tumour-free at the experimental endpoint, 28 days after cell injection (Figure $1 \mathrm{~A}$ and B). Six of the 20 mice that received anti-asialo a day before injection with 500,000 cells developed metastases that were detectable in vivo within 28 days (Figure 1A and B). More sensitive ex vivo imaging revealed that an additional three NK-depleted mice harboured metastases. Metastases were detected ex vivo in multiple organs, including the lungs, liver, kidneys, brain, and heart, in addition to bones and muscles (Figure 1A, C and D).

We conclude that NK depletion boosts the efficiency of experimental metastasis for Ewing sarcoma, as it did for osteosarcoma (41), and Ewing metastases formed in multiple anatomical sites. However, using up to half a million cells only produced metastases in half of the animals, illustrating the inefficiency of this approach.

Injection of A673 cells into the tibialis anterior consistently resulted in the formation of distant metastases. A673 cells were injected intramuscularly into the gastrocnemius muscle in other studies that failed to detect extra-pulmonary metastases $(34,36)$, however we opted for the tibialis anterior muscle as we had previously observed that osteosarcomas created via cell inoculation into this muscle were well-tolerated and formed metastases in multiple organs $(37,38)$. In previous studies, authors injected millions of cells intramuscularly, which necessitated resection of the primary tumour to allow the mice to survive long enough for lung metastases to develop $(34,36)$. As tumour resection is invasive and not always complete, we injected ten mice with only 50,000 A673-luc cells, in the hope that a smaller primary tumour in a well-tolerated site would allow the mice to survive longer, giving more time for cells to metastasise from the primary tumour. One mouse developed a subcutaneous tumour, presumably reflecting incorrect needle placement - that mouse was excluded from the experiment. Another failed to develop a tumour by 70 days after cell injection. The remaining eight mice injected with A673-luc cells developed intramuscular tumours (Figure 2A and B). Invasion of the tumour cells into the surrounding muscle was confirmed by haematoxylin and eosin staining (Figure 2C). Mice were kept alive for a maximum of 70 days, but were euthanised if/when their primary tumour exceeded $1 \mathrm{~cm} 3$ or became ulcerated, or the limb bearing the tumour became paralysed. Most had to be euthanised within four weeks of cell inoculation (Figure 2D). Although bioluminescence from metastases was not evident in vivo, ex vivo analyses revealed that all mice bearing intramuscular tumours harboured metastases in their lungs, liver, heart, kidneys, brain, and one mouse also bore a metastasis in its left hamstring (Figure 2A, $\mathrm{E}$ and $\mathrm{F}$ ). None of these metastases provoked symptoms requiring euthanasia within 70 days of cell inoculation. Other organs were imaged ex vivo for the presence of bioluminescent metastases, but none were detected.

Ewing sarcoma metastases had higher immune cell infiltration than primary intramuscular tumours. Having established metastatic models of extraskeletal Ewing sarcoma in the presence and absence of primary tumours, we next characterised the cellular composition of the primary tumours and metastases. This study used BALB/c nude mice, which have vastly reduced numbers of adaptive immune cells. They do, however, possess innate immune cells including macrophages (45), which are the most abundant infiltrating cell type in clinical Ewing sarcoma specimens $(46,47)$, and NK cells and neutrophils, which are minor constituents of patient tumours $(46,47)$. Most cells in the primary xenografts and metastases were A673-luc cells, with very few infiltrating immune cells (Figure 3A and B). Interestingly, natural killer cells accounted for a significantly larger proportion of cells within metastases than primary tumours (Figure 3C), which may have contributed to the inconsistent formation of metastases after intravenous injection of cells into NK-depleted animals. There were also larger proportions of neutrophils and macrophages in metastases than primary tumours, however these differences were not statistically significant (Figure 3C).

\section{Discussion}

Compared to skeletal Ewing sarcomas, which metastasise preferentially to the lung, bone and bone marrow, extraskeletal Ewing sarcomas feature more extensive metastatic tropism $(12,13)$. It was therefore surprising that previous reports of mouse models of this form of the disease, which typically involved introducing unlabelled A673 cells into the tail vein and/or gastrocnemius muscle, only mentioned lung metastases $(33-35,39,48)$. While it is possible that those researchers may have overlooked metastases elsewhere, other studies used luciferaseexpressing cells, which would have facilitated detection of 


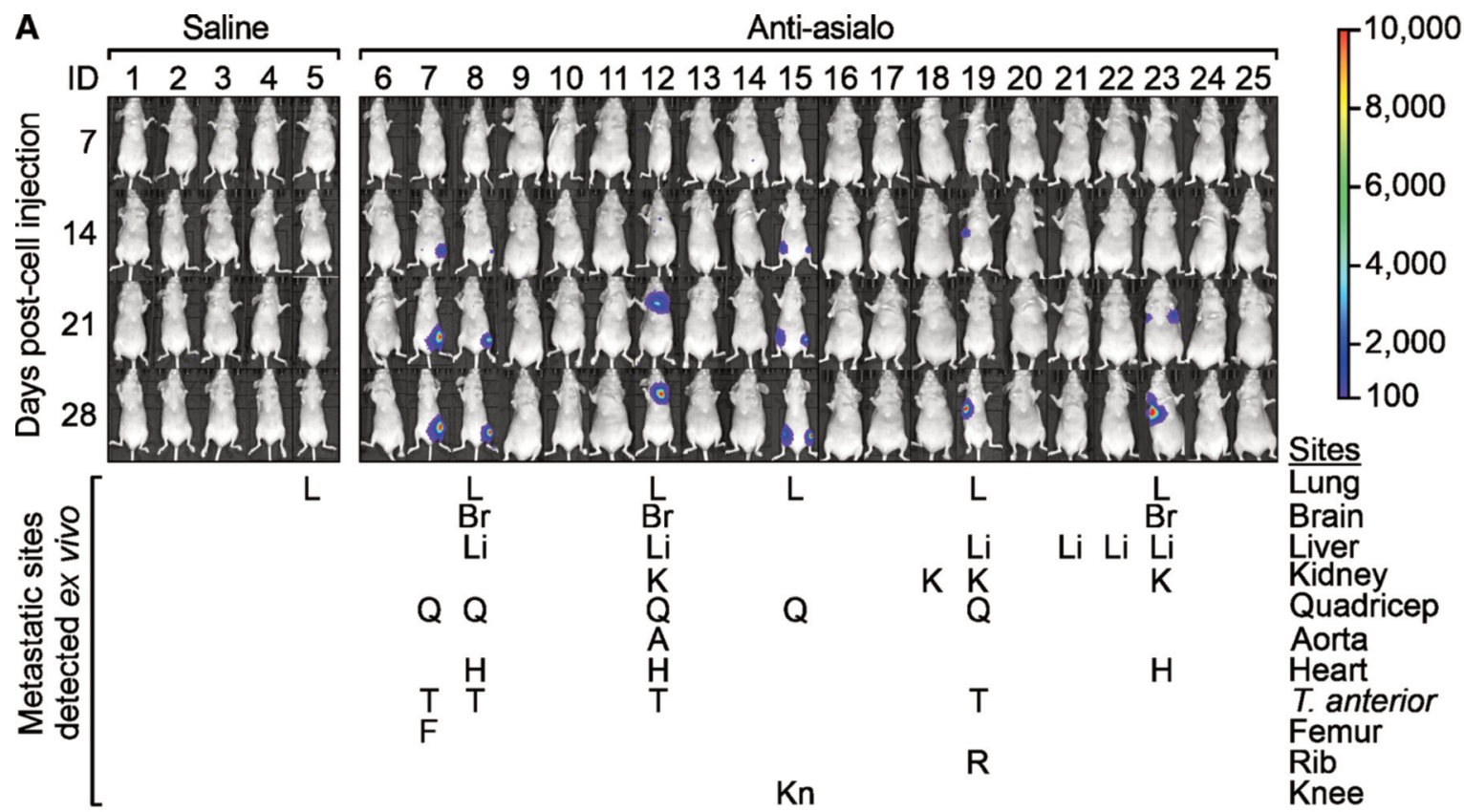

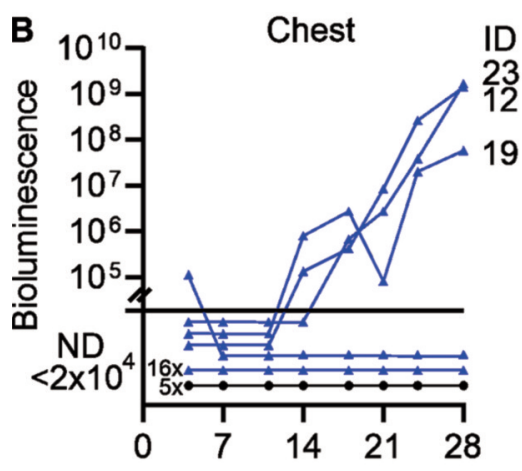

Days post-cell injection

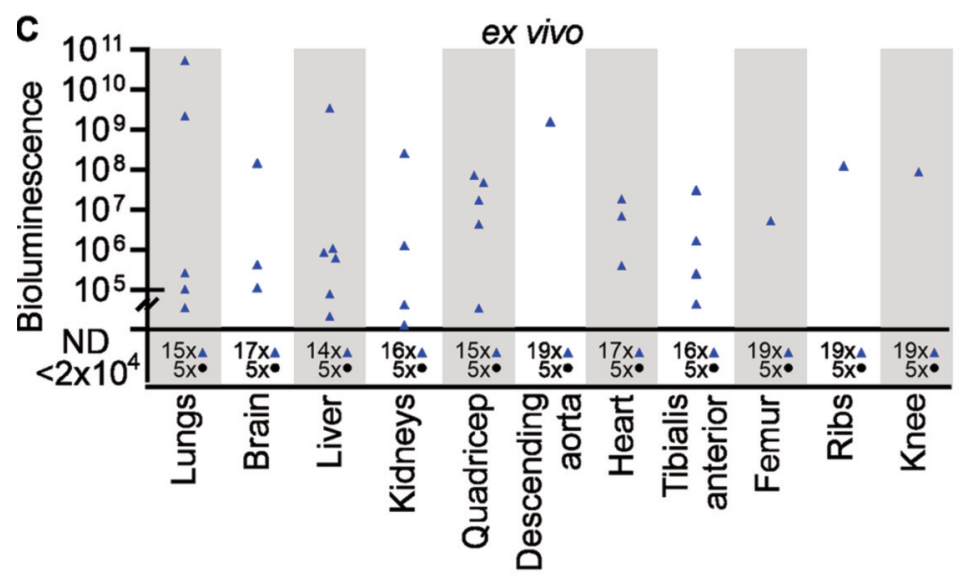

Abdomen
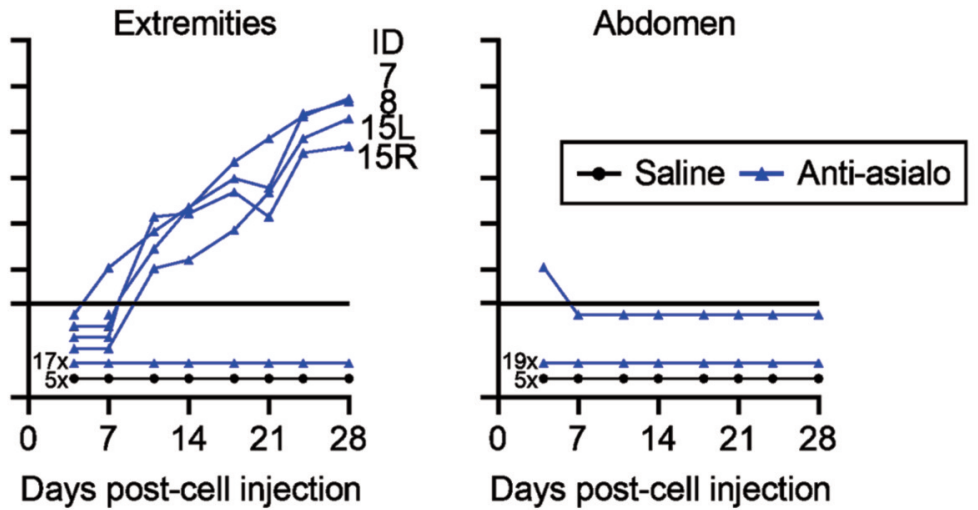

D

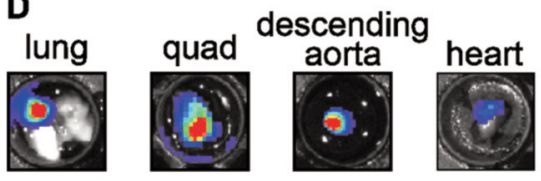

tibialis

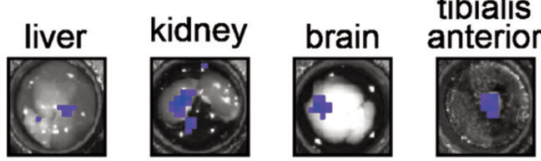

Figure 1. Intravenous administration of 500,000 A673-luc cells in BALB/c nude mice that were injected with saline or anti-asialo GM1 24 hours prior to injection of cells. (A) Compiled in vivo bioluminescence images of mice. Sites of metastases that were detected ex vivo in each mouse are indicated below the images. (B) Bioluminescence within the chest, abdomen, extremities, and head were measured over time. Individual mice with detectable signals at day 28 are specified with I.D. numbers to the right of the curves. The signal detection limit was 20,000. The mice in each group with undetectable bioluminescence at each timepoint are indicated under each graph in the region labelled "ND" (not detected). (C) Bioluminescence of resected tissue was measured after mice were euthanised. (D) Representative ex vivo images of tissue containing metastases. 

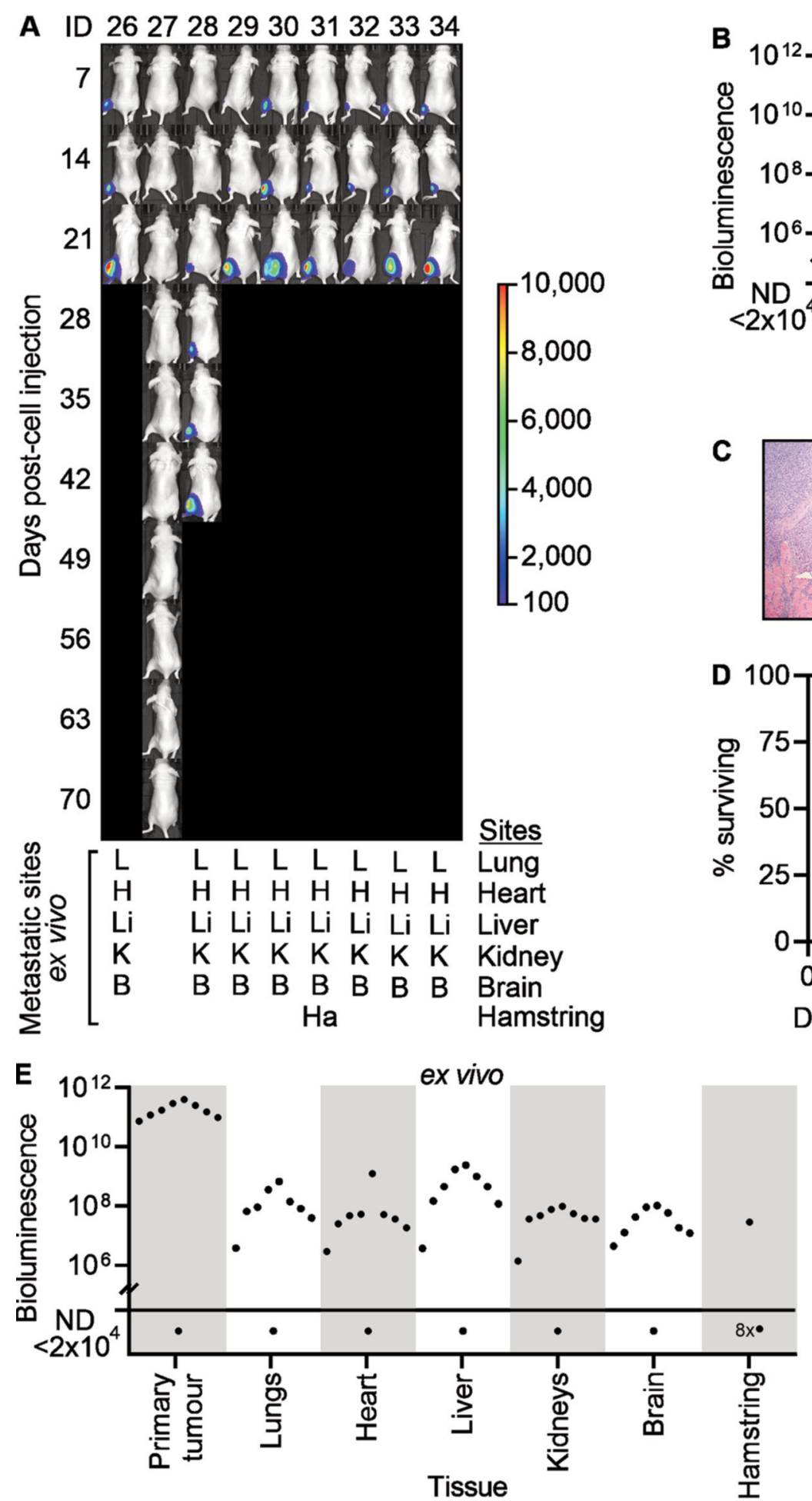

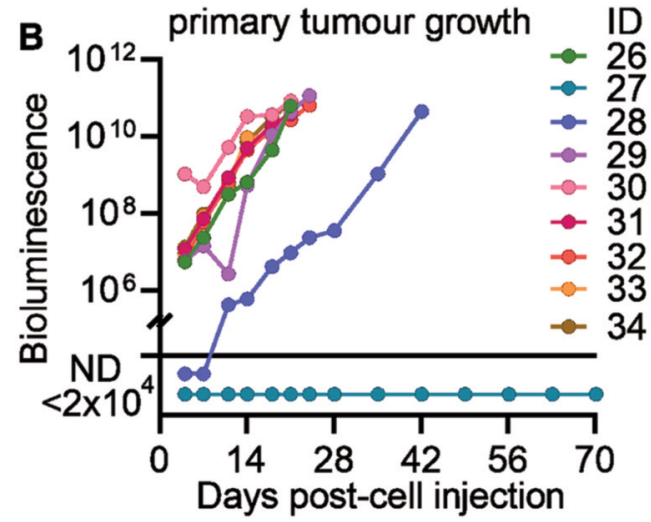

C
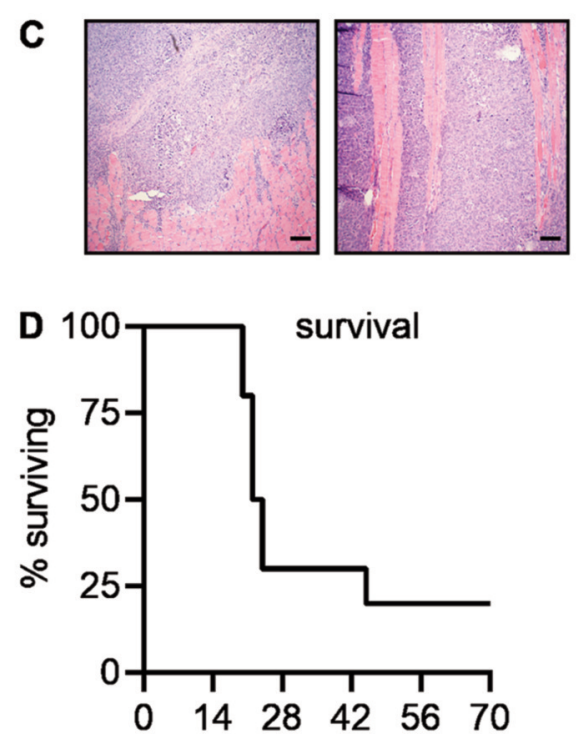

Days post cells injection

$\mathbf{F}$
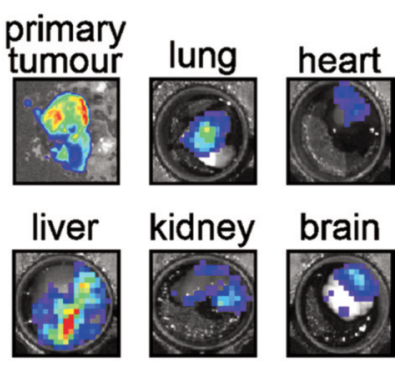

Figure 2. Intramuscular injection of 50,000 A673-luc cells into the tibialis anterior muscle of BALB/c nude mice. (A) Compiled in vivo bioluminescence images of mice. Sites of metastases that were detected ex vivo in each mouse are indicated below the images. (B) Bioluminescence reflecting primary tumour growth in the legs was measured. The signal detection limit was 20,000. The mice with undetectable bioluminescence at each timepoint are indicated under each graph in the region labelled "ND" (not detected). (C) Two primary tumours were analysed by haematoxylin and eosin staining (scale bars $=50 \mu \mathrm{m}$ ). (D) Survival after intramuscular injection of cells was monitored. (E) Bioluminescence of resected tissue was measured after mice were euthanised. $(F)$ Representative ex vivo images of tissue containing metastases. 
A Primary tumours
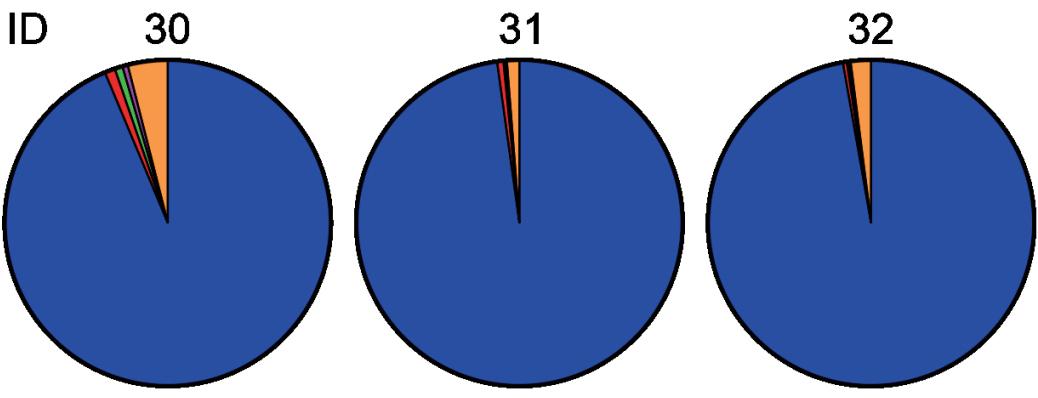

\section{B Metastases}
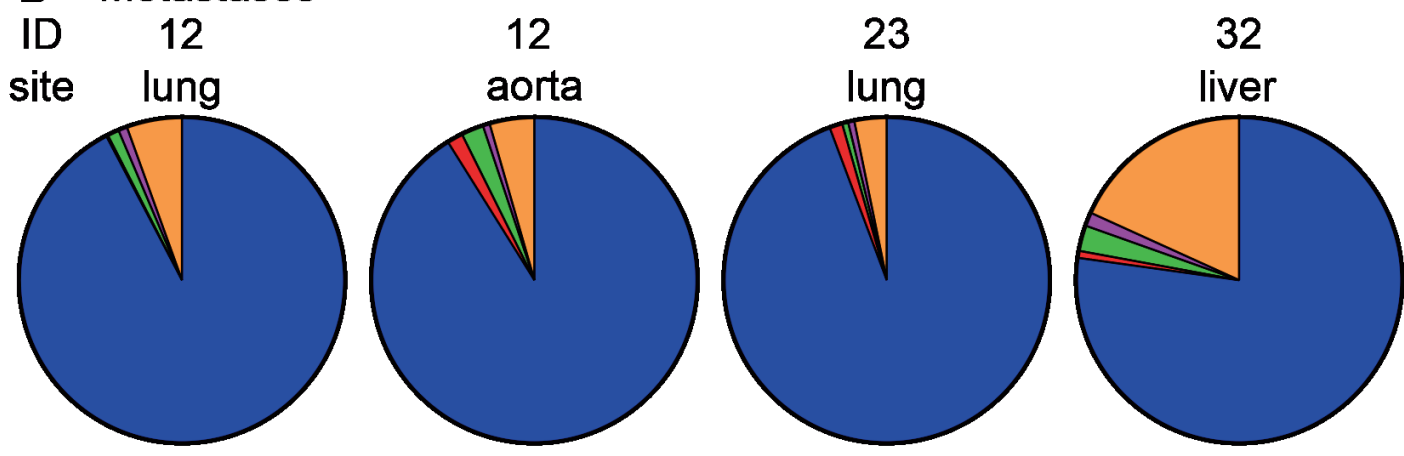

$\square$ Ewing sarcoma cells: dTomato+

$\square$ Neutrophils: dTomato-, Ly6G+

$\square$ Macrophages: dTomato-, Ly6G-, F4/80+

$\square$ NK cells: dTomato-, Ly6G-, F4/80-, NKp46+

$\square$ Other: dTomato-, Ly6G-, F4/80-, NKp46-

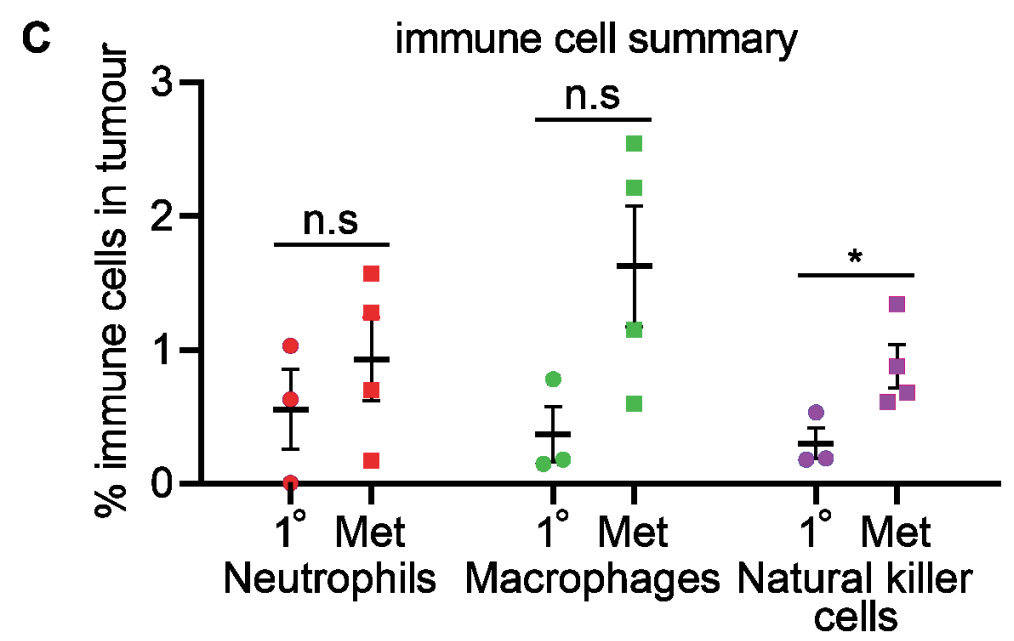

Figure 3. Immune cell profiling of A673-luc primary intramuscular tumours and metastases. Immune cell profiling was performed on (A) three primary intramuscular tumours (circles) and (B) four metastases (squares). (C) A graphical summary of the data is provided. 
even small metastases. Those researchers failed to detect extrapulmonary metastases after injection of A673 cells into the gastrocnemius muscle (36) or only observed spread to the lungs and bones after intratibial inoculation (24). In contrast, we detected metastases in numerous sites following either intravenous injection of luciferase-labelled A673 cells into transiently NK-depleted animals or due to spontaneous spread from primary tumours in the tibialis anterior muscle. The diverse metastatic pattern achieved in these models could enable evaluation of the efficacy of candidate treatments against metastases located in various organs.

The difference in metastatic tropism achieved in this study compared to previous reports could be due to differences in the cells or methods used to introduce them into the mice. The short tandem repeat genotype of our A673 cells matched published profiles (49-51) but it is possible that our cells have subtle genetic or epigenetic changes that account for their more diverse metastatic predilection.

It is also possible that the methods used in this study have contributed to the enhanced ability of A673 cells to colonise multiple organs and tissues. Temporary depletion of NK cells prior to intravenous injection of cells increased metastatic efficiency. Without this pre-treatment, none of the mice injected with 500,000 A673 cells developed metastases, yet metastases arose in various organs of many of the animals whose NK cells had been transiently depleted. In previously published experimental metastasis experiments, 2-5 million A673 cells were used, and only lung metastases were reported $(33-35,39)$. We hypothesise that NK cells may have a particularly pronounced impact on the spread of A673 cells to organs other than the lungs. Consistent with that notion, the only previous model that demonstrated extra-pulmonary metastasis of A673 cells employed NOD/SCID mice (24), which lack NK cells (52).

Published intramuscular models involved injecting two million A673 cells into the murine gastrocnemius muscle. We assume this large number of cells was required to achieve reproducible tumourigenicity using this method. Researchers who used this approach to investigate metastases resected primary tumours when they reached $800-1000 \mathrm{~mm}^{3}$ to extend survival until metastases formed. Lung metastases formed in most animals on which this procedure was performed within 60 days of cell implantation (34-36). In this study, almost all mice developed tumours following injection of only 50,000 cells into the tibialis anterior muscle: 40 -fold fewer cells than are evidently required to reliably form tumours upon implantation into the gastrocnemius muscle. The tibialis anterior tumours were universally metastatic to the lung, heart, liver, kidney, and brain by the time primary tumour growth necessitated euthanasia. Although the mice had to be euthanised due to primary tumour size or symptoms before their metastases could be imaged in vivo, the consistency of the metastatic pattern suggests this model could be used to assess the impact of candidate therapies on metastatic burden.
Resection of the primary tumour would presumably enable the mice to survive long enough for the metastases to be detectable in vivo, and ultimately to provoke symptoms. It seems that introducing A673 cells into the tibialis anterior rather than gastrocnemius muscle boosts the efficiency of tumourigenesis and facilitates spread to a greater diversity of sites. Further research will be needed to explore whether differences between these muscles with respect to their vascularisation or other anatomical or physiological features account for the apparent difference in metastatic potential of these primary tumours, and whether this mirrors clinical observations.

Prior work demonstrated minor immune cell involvement in Ewing sarcomas, contrasting with osteosarcomas (53). Our intramuscular model recapitulates this, as scarce immune cell infiltration was identified in both primary and metastatic tumours. It was interesting that the metastases that we analysed contained a higher frequency of innate immune cells than the primary intramuscular tumours. Further work will be needed to explore whether muscles provide a less hospitable microenvironment for these innate immune cells than the metastatic sites we examined. Unfortunately, it is currently unclear whether this trend also exists in patient specimens, as very little is currently known about the cellular composition of Ewing metastases (10). However, the observation that Ewing metastases contained more PD-L1expressing cells than primary tumours (54) suggests immune profiles of metastases and primary tumours may differ.

This study established two novel mouse models of extraskeletal Ewing sarcoma that feature diverse sites of metastatic spread, reflecting clinical patterns of metastatic tropism. An orthotopic model in which luciferase-expressing A673 Ewing sarcoma cells were introduced into the tibialis anterior muscle of mice yielded highly efficient and reproducible primary tumours and invariant spread to the lungs, heart, liver, kidneys and brain. Macrophages, neutrophils and NK cells were rare in these primary tumours, but were more plentiful in metastases. Transient depletion of natural killer cells increased the efficiency and extent of metastatic spread of A673 cells in an experimental metastasis model. We hope that these experimental models will help researchers to gain a better understanding of this disease and to test future therapies that may improve outcomes for extraskeletal Ewing sarcoma patients.

\section{Conflicts of Interest}

The Authors declare no conflicts of interest in relation to this study.

\section{Authors' Contributions}

MAH and CJH designed the experiments. $\mathrm{CC}$ and MAH conducted the experiments. MAH and CC analysed the data. MAH, CC and $\mathrm{CJH}$ and wrote the manuscript. CJH supervised the project and obtained funding. 


\section{Acknowledgements}

The authors would like to thank Lucy Coupland for the A673 cells, the La Trobe Institute for Molecular Science BioImaging Facility for assistance with flow cytometry and microscopy, and the La Trobe Animal Research and Training Facility for assistance with animal experiments. This study was funded by grants from The Kids' Cancer Project, Cancer Council Victoria and Tour de Cure.

\section{References}

1 Doyle LA: Sarcoma classification: an update based on the 2013 World Health Organization Classification of Tumors of Soft Tissue and Bone. Cancer 120(12): 1763-1774, 2014. PMID: 24648013. DOI: $10.1002 / \mathrm{cncr} .28657$

2 Ewing J: Classics in oncology. Diffuse endothelioma of bone. James Ewing. Proceedings of the New York Pathological Society, 1921. CA Cancer J Clin 22(2): 95-98, 1972. PMID: 4622125. DOI: 10.3322/canjclin.22.2.95

3 Stiller CA, Trama A, Serraino D, Rossi S, Navarro C, Chirlaque MD, Casali PG and RARECARE Working Group: Descriptive epidemiology of sarcomas in Europe: report from the RARECARE project. Eur J Cancer 49(3): 684-695, 2013. PMID: 23079473. DOI: 10.1016/j.ejca.2012.09.011

4 Abboud A, Masrouha K, Saliba M, Haidar R, Saab R, Khoury N, Tawil A and Saghieh S: Extraskeletal Ewing sarcoma: Diagnosis, management and prognosis. Oncol Lett 21(5): 354, 2021. PMID: 33747211. DOI: 10.3892/ol.2021.12615

5 Hesla AC, Papakonstantinou A and Tsagkozis P: Current status of management and outcome for patients with Ewing sarcoma. Cancers (Basel) 13(6): 1202, 2021. PMID: 33801953. DOI: 10.3390/cancers 13061202

6 Applebaum MA, Worch J, Matthay KK, Goldsby R, Neuhaus J, West DC and Dubois SG: Clinical features and outcomes in patients with extraskeletal Ewing sarcoma. Cancer 117(13): 3027-3032, 2011. PMID: 21692057. DOI: 10.1002/cncr.25840

7 Jiang S, Wang G, Chen J and Dong Y: Comparison of clinical features and outcomes in patients with extraskeletal vs skeletal Ewing sarcoma: an SEER database analysis of 3,178 cases. Cancer Manag Res 10: 6227-6236, 2018. PMID: 30538569. DOI: $10.2147 /$ CMAR.S178979

8 Smorenburg $\mathrm{CH}$, van Groeningen CJ, Meijer OW, Visser M and Boven E: Ewing's sarcoma and primitive neuroectodermal tumour in adults: single-centre experience in The Netherlands. Neth J Med 65(4): 132-136, 2007. PMID: 17452761.

9 Baldini EH, Demetri GD, Fletcher CD, Foran J, Marcus KC and Singer S: Adults with Ewing's sarcoma/primitive neuroectodermal tumor: adverse effect of older age and primary extraosseous disease on outcome. Ann Surg 230(1): 79-86, 1999. PMID: 10400040. DOI: 10.1097/00000658-199907000-00012

10 Zöllner SK, Amatruda JF, Bauer S, Collaud S, de Álava E, DuBois SG, Hardes J, Hartmann W, Kovar H, Metzler M, Shulman DS, Streitbürger A, Timmermann B, Toretsky JA, Uhlenbruch Y, Vieth V, Grünewald TGP and Dirksen U: Ewing sarcoma-diagnosis, treatment, clinical challenges and future perspectives. J Clin Med 10(8): 1685, 2021. PMID: 33919988. DOI: $10.3390 / \mathrm{jcm} 10081685$

11 Worch J, Ranft A, DuBois SG, Paulussen M, Juergens H and Dirksen U: Age dependency of primary tumor sites and metastases in patients with Ewing sarcoma. Pediatr Blood
Cancer 65(9): e27251, 2018. PMID: 29856530. DOI: $10.1002 / \mathrm{pbc} .27251$

12 Huh J, Kim KW, Park SJ, Kim HJ, Lee JS, Ha HK, Tirumani SH and Ramaiya NH: Imaging features of primary tumors and metastatic patterns of the extraskeletal Ewing sarcoma family of tumors in adults: A 17-year experience at a single institution. Korean J Radiol 16(4): 783-790, 2015. PMID: 26175577. DOI: 10.3348/kjr.2015.16.4.783

13 Ushigusa J, Mukae Y, Takamatsu M, Nogami E, Furutachi A, Itoh M, Yunoki J and Nishida T: Adult-onset primary Ewing's sarcoma of the right atrium: a case report. Surg Case Rep 5(1): 171, 2019. PMID: 31696353. DOI: 10.1186/s40792-019-0727-1

14 Womer RB, West DC, Krailo MD, Dickman PS, Pawel BR, Grier HE, Marcus K, Sailer S, Healey JH, Dormans JP and Weiss AR: Randomized controlled trial of interval-compressed chemotherapy for the treatment of localized Ewing sarcoma: a report from the Children's Oncology Group. J Clin Oncol 30(33): 4148-4154, 2012. PMID: 23091096. DOI: 10.1200/JCO.2011.41.5703

15 Ludwig JA: Ewing sarcoma: historical perspectives, current state-of-the-art, and opportunities for targeted therapy in the future. Curr Opin Oncol 20(4): 412-418, 2008. PMID: 18525337. DOI: $10.1097 / C C O .0 b 013 e 328303$ ba1d

16 Lessnick SL and Ladanyi M: Molecular pathogenesis of Ewing sarcoma: new therapeutic and transcriptional targets. Annu Rev Pathol 7: 145-159, 2012. PMID: 21942527. DOI: 10.1146/ annurev-pathol-011110-130237

17 Minas TZ, Surdez D, Javaheri T, Tanaka M, Howarth M, Kang HJ, Han J, Han ZY, Sax B, Kream BE, Hong SH, Çelik H, Tirode F, Tuckermann J, Toretsky JA, Kenner L, Kovar H, Lee S, Sweet-Cordero EA, Nakamura T, Moriggl R, Delattre O and Üren A: Combined experience of six independent laboratories attempting to create an Ewing sarcoma mouse model. Oncotarget 8(21): 34141-34163, 2017. PMID: 27191748. DOI: 10.18632/ oncotarget 9388

18 Cidre-Aranaz F and Ohmura S: Tumor growth analysis of Ewing sarcoma cell lines using subcutaneous xenografts in mice. Methods Mol Biol 2226: 191-199, 2021. PMID: 33326103. DOI: 10.1007/978-1-0716-1020-6_15

19 Ordóñez JL, Amaral AT, Carcaboso AM, Herrero-Martín D, del Carmen García-Macías M, Sevillano V, Alonso D, Pascual-Pasto G, San-Segundo L, Vila-Ubach M, Rodrigues T, Fraile S, Teodosio C, Mayo-Iscar A, Aracil M, Galmarini CM, Tirado $\mathrm{OM}$, Mora $\mathrm{J}$ and de Álava E: The PARP inhibitor olaparib enhances the sensitivity of Ewing sarcoma to trabectedin. Oncotarget 6(22): 18875-18890, 2015. PMID: 26056084. DOI: 10.18632/oncotarget.4303

20 Nanni P, Landuzzi L, Manara MC, Righi A, Nicoletti G, Cristalli C, Pasello M, Parra A, Carrabotta M, Ferracin M, Palladini A, Ianzano ML, Giusti V, Ruzzi F, Magnani M, Donati DM, Picci P, Lollini PL and Scotlandi K: Bone sarcoma patient-derived xenografts are faithful and stable preclinical models for molecular and therapeutic investigations. Sci Rep 9(1): 12174, 2019. PMID: 31434953. DOI: 10.1038/s41598019-48634-y

21 Surdez D, Landuzzi L, Scotlandi K and Manara MC: Ewing Sarcoma PDX Models. Methods Mol Biol 2226: 223-242, 2021. PMID: 33326106. DOI: 10.1007/978-1-0716-1020-6_18

22 Vormoor B, Knizia HK, Batey MA, Almeida GS, Wilson I, Dildey P, Sharma A, Blair H, Hide IG, Heidenreich O, Vormoor J, Maxwell RJ and Bacon CM: Development of a preclinical 
orthotopic xenograft model of ewing sarcoma and other human malignant bone disease using advanced in vivo imaging. PLoS One 9(1): e85128, 2014. PMID: 24409320. DOI: 10.1371/ journal.pone.0085128

23 Odri GA, Dumoucel S, Picarda G, Battaglia S, Lamoureux F, Corradini N, Rousseau J, Tirode F, Laud K, Delattre O, Gouin F, Heymann D and Redini F: Zoledronic acid as a new adjuvant therapeutic strategy for Ewing's sarcoma patients. Cancer Res 70(19): 7610-7619, 2010. PMID: 20841471. DOI: 10.1158/ 0008-5472.CAN-09-4272

24 Chaturvedi A, Hoffman LM, Jensen CC, Lin YC, Grossmann AH, Randall RL, Lessnick SL, Welm AL and Beckerle MC: Molecular dissection of the mechanism by which EWS/FLI expression compromises actin cytoskeletal integrity and cell adhesion in Ewing sarcoma. Mol Biol Cell 25(18): 2695-2709, 2014. PMID: 25057021. DOI: 10.1091/mbc.E14-01-0007

25 Stewart E, Federico SM, Chen X, Shelat AA, Bradley C, Gordon B, Karlstrom A, Twarog NR, Clay MR, Bahrami A, Freeman BB 3rd, Xu B, Zhou X, Wu J, Honnell V, Ocarz M, Blankenship K, Dapper J, Mardis ER, Wilson RK, Downing J, Zhang J, Easton J, Pappo A and Dyer MA: Orthotopic patient-derived xenografts of paediatric solid tumours. Nature 549(7670): 96-100, 2017. PMID: 28854174. DOI: 10.1038/nature23647

26 Whang-Peng J, Triche TJ, Knutsen T, Miser J, Kao-Shan S, Tsai $\mathrm{S}$ and Israel MA: Cytogenetic characterization of selected small round cell tumors of childhood. Cancer Genet Cytogenet 21(3): 185-208, 1986. PMID: 3004699. DOI: 10.1016/0165-4608(86) 90001-4

27 Komuro H, Hayashi Y, Kawamura M, Hayashi K, Kaneko Y, Kamoshita S, Hanada R, Yamamoto K, Hongo T and Yamada M: Mutations of the p53 gene are involved in Ewing's sarcomas but not in neuroblastomas. Cancer Res 53(21): 5284-5288, 1993. PMID: 8221663.

28 Bloom ET: Further definition by cytotoxicity tests of cell surface antigens of human sarcomas in culture. Cancer Res 32(5): 960967, 1972. PMID: 4502173.

29 Hong SH, Tilan JU, Galli S, Izycka-Swieszewska E, Polk T, Horton M, Mahajan A, Christian D, Jenkins S, Acree R, Connors K, Ledo P, Lu C, Lee YC, Rodriguez O, Toretsky JA, Albanese $\mathrm{C}$ and Kitlinska J: High neuropeptide $\mathrm{Y}$ release associates with Ewing sarcoma bone dissemination - in vivo model of sitespecific metastases. Oncotarget 6(9): 7151-7165, 2015. PMID: 25714031. DOI: 10.18632/oncotarget.3345

30 Giard DJ, Aaronson SA, Todaro GJ, Arnstein P, Kersey JH, Dosik H and Parks WP: In vitro cultivation of human tumors: establishment of cell lines derived from a series of solid tumors. J Natl Cancer Inst 51(5): 1417-1423, 1973. PMID: 4357758. DOI: $10.1093 /$ jnci/51.5.1417

31 Roberts I, Wienberg J, Nacheva E, Grace C, Griffin D and Coleman N: Novel method for the production of multiple colour chromosome paints for use in karyotyping by fluorescence in situ hybridisation. Genes Chromosomes Cancer 25(3): 241-250, 1999. PMID: 10379870. DOI: 10.1002/(sici)1098-2264(199907) 25:3<241::aid-gcc6>3.0.co;2-7

32 Martínez-Ramírez A, Rodríguez-Perales S, Meléndez B, Martínez-Delgado B, Urioste M, Cigudosa JC and Benítez J: Characterization of the A673 cell line (Ewing tumor) by molecular cytogenetic techniques. Cancer Genet Cytogenet 141(2): 138-142, 2003. PMID: 12606131. DOI: 10.1016/s01654608(02)00670-2
33 Picarda G, Lamoureux F, Geffroy L, Delepine P, Montier T, Laud K, Tirode F, Delattre O, Heymann D and Rédini F: Preclinical evidence that use of TRAIL in Ewing's sarcoma and osteosarcoma therapy inhibits tumor growth, prevents osteolysis, and increases animal survival. Clin Cancer Res 16(8): 23632374, 2010. PMID: 20371692. DOI: 10.1158/1078-0432.CCR09-1779

34 Lagares-Tena L, García-Monclús S, López-Alemany R, Almacellas-Rabaiget O, Huertas-Martínez J, Sáinz-Jaspeado M, Mateo-Lozano S, Rodríguez-Galindo C, Rello-Varona S, Herrero-Martín D and Tirado OM: Caveolin-1 promotes Ewing sarcoma metastasis regulating MMP-9 expression through MAPK/ERK pathway. Oncotarget 7(35): 56889-56903, 2016. PMID: 27487136. DOI: 10.18632/oncotarget.10872

35 Garcia-Monclús S, López-Alemany R, Almacellas-Rabaiget O, Herrero-Martín D, Huertas-Martinez J, Lagares-Tena L, AlbaPavón P, Hontecillas-Prieto L, Mora J, de Álava E, Rello-Varona $\mathrm{S}$, Giangrande $\mathrm{PH}$ and Tirado OM: EphA2 receptor is a key player in the metastatic onset of Ewing sarcoma. Int J Cancer 143(5): 1188-1201, 2018. PMID: 29582409. DOI: 10.1002/ijc.31405

36 López-Alemany R and Tirado OM: Metastasis assessment in Ewing sarcoma using orthotopic xenografts. Methods Mol Biol 2226: 201-213, 2021. PMID: 33326104. DOI: 10.1007/978-10716-1020-6_16

37 Harris MA, Miles MA, Shekhar TM, Cerra C, Georgy SR, Ryan SD, Cannon CM and Hawkins CJ: The proteasome inhibitor ixazomib inhibits the formation and growth of pulmonary and abdominal osteosarcoma metastases in mice. Cancers (Basel) 12(5): 1207, 2020. PMID: 32403415. DOI: 10.3390/cancers 12051207

38 Shekhar TM, Burvenich IJG, Harris MA, Rigopoulos A, Zanker D, Spurling A, Parker BS, Walkley CR, Scott AM and Hawkins CJ: Smac mimetics LCL161 and GDC-0152 inhibit osteosarcoma growth and metastasis in mice. BMC Cancer 19(1): 924, 2019. PMID: 31521127. DOI: 10.1186/s12885-0196103-5

39 Sáinz-Jaspeado M, Lagares-Tena L, Lasheras J, Navid F, Rodriguez-Galindo C, Mateo-Lozano S, Notario V, Sanjuan X, Garcia Del Muro X, Fabra A and Tirado OM: Caveolin-1 modulates the ability of Ewing's sarcoma to metastasize. Mol Cancer Res 8(11): 1489-1500, 2010. PMID: 21106507. DOI: 10.1158/1541-7786.MCR-10-0060

40 Richter GH, Plehm S, Fasan A, Rössler S, Unland R, BennaniBaiti IM, Hotfilder M, Löwel D, von Luettichau I, Mossbrugger I, Quintanilla-Martinez L, Kovar H, Staege MS, Müller-Tidow C and Burdach S: EZH2 is a mediator of EWS/FLI1 driven tumor growth and metastasis blocking endothelial and neuro-ectodermal differentiation. Proc Natl Acad Sci USA 106(13): 5324-5329, 2009. PMID: 19289832. DOI: 10.1073/pnas.0810759106

41 Harris MA, Hons B, Shekhar TM, Coupland LA, Miles MA and Hawkins CJ: Transient NK cell depletion facilitates pulmonary osteosarcoma metastases after intravenous inoculation in athymic mice. J Adolesc Young Adult Oncol 9(6): 667-671, 2020. PMID: 32397787. DOI: 10.1089/jayao.2019.0172

42 Coupland LA, Chong BH and Parish CR: Beware of NK cells in pre-clinical metastasis models. Clin Exp Metastasis 30(7): 945-947, 2013. PMID: 23605848. DOI: 10.1007/s10585-0139582-9

43 Patel MR, Chang YF, Chen IY, Bachmann MH, Yan X, Contag $\mathrm{CH}$ and Gambhir SS: Longitudinal, noninvasive imaging of Tcell effector function and proliferation in living subjects. Cancer 
Res 70(24): 10141-10149, 2010. PMID: 21159636. DOI: 10.1158/0008-5472.CAN-10-1843

44 Gross A, Schoendube J, Zimmermann S, Steeb M, Zengerle R and Koltay P: Technologies for single-cell isolation. Int J Mol Sci 16(8): 16897-16919, 2015. PMID: 26213926. DOI: 10.3390/ijms 160816897

45 Budzynski W and Radzikowski C: Cytotoxic cells in immunodeficient athymic mice. Immunopharmacol Immunotoxicol 16(3): 319-346, 1994. PMID: 7528237. DOI: 10.3109/0892397 9409007097

46 Inagaki Y, Hookway E, Williams KA, Hassan AB, Oppermann U, Tanaka Y, Soilleux E and Athanasou NA: Dendritic and mast cell involvement in the inflammatory response to primary malignant bone tumours. Clin Sarcoma Res 6: 13, 2016. PMID: 27482375. DOI: 10.1186/s13569-016-0053-3

47 Stahl D, Gentles AJ, Thiele R and Gütgemann I: Prognostic profiling of the immune cell microenvironment in Ewing's Sarcoma Family of Tumors. Oncoimmunology 8(12): e1674113, 2019. PMID: 31741777. DOI: 10.1080/2162402X.2019.1674113

48 Dear RF, Kelly PJ, Wright GM, Stalley P, McCaughan BC and Tattersall MH: Pulmonary metastasectomy for bone and soft tissue sarcoma in Australia: 114 patients from 1978 to 2008. Asia Pac J Clin Oncol 8(3): 292-302, 2012. PMID: 22897801. DOI: $10.1111 / \mathrm{j} .1743-7563.2012 .01521 . x$

49 Yu M, Selvaraj SK, Liang-Chu MM, Aghajani S, Busse M, Yuan J, Lee G, Peale F, Klijn C, Bourgon R, Kaminker JS and Neve RM: A resource for cell line authentication, annotation and quality control. Nature 520(7547): 307-311, 2015. PMID: 25877200. DOI: $10.1038 /$ nature 14397

50 Brohl AS, Solomon DA, Chang W, Wang J, Song Y, Sindiri S, Patidar R, Hurd L, Chen L, Shern JF, Liao H, Wen X, Gerard J, Kim JS, Lopez Guerrero JA, Machado I, Wai DH, Picci P, Triche
T, Horvai AE, Miettinen M, Wei JS, Catchpool D, LlombartBosch A, Waldman T and Khan J: The genomic landscape of the Ewing Sarcoma family of tumors reveals recurrent STAG2 mutation. PLoS Genet 10(7): e1004475, 2014. PMID: 25010205. DOI: 10.1371/journal.pgen.1004475

51 May WA, Grigoryan RS, Keshelava N, Cabral DJ, Christensen LL, Jenabi J, Ji L, Triche TJ, Lawlor ER and Reynolds CP: Characterization and drug resistance patterns of Ewing's sarcoma family tumor cell lines. PLoS One 8(12): e80060, 2013. PMID: 24312454. DOI: 10.1371/journal.pone.0080060

52 Shultz LD, Schweitzer PA, Christianson SW, Gott B, Schweitzer IB, Tennent B, McKenna S, Mobraaten L, Rajan TV and Greiner DL: Multiple defects in innate and adaptive immunologic function in NOD/LtSz-scid mice. J Immunol 154(1): 180-191, 1995. PMID: 7995938.

53 Dyson KA, Stover BD, Grippin A, Mendez-Gomez HR, Lagmay J, Mitchell DA and Sayour EJ: Emerging trends in immunotherapy for pediatric sarcomas. J Hematol Oncol 12(1): 78, 2019. PMID: 31311607. DOI: 10.1186/s13045-019-0756-Z

54 Machado I, López-Guerrero JA, Scotlandi K, Picci P and Llombart-Bosch A: Immunohistochemical analysis and prognostic significance of PD-L1, PD-1, and CD8+ tumorinfiltrating lymphocytes in Ewing's sarcoma family of tumors (ESFT). Virchows Arch 472(5): 815-824, 2018. PMID: 29445891. DOI: $10.1007 / \mathrm{s} 00428-018-2316-2$

Received July 26, 2021

Revised August 5, 2021

Accepted August 6, 2021 